\title{
The Effects of the Types of Healthy Leisure Program on the Falls Efficacy and Cognition of Low-Income Elderly Women
}

\author{
Mi-Ran Lee ${ }^{1}$ and Seon-Hee Kim ${ }^{2 *}$ \\ ${ }^{1,2}$ Department of Social Welfare, Kosin University, \\ 194 Wachi-Ro Yeongdo-Gu, Busan, Korea \\ 1dsmr0815@naver.com
}

\begin{abstract}
This study applied various types of healthy leisure programs focusing on laughter therapy, music therapy, massage therapy, and art therapy to low-income elderly women for the purpose of improving their health and rehabilitation, and analyzed the effects of the program on the changes in falls efficacy and cognition. A total of 80 elderly women were divided into four groups of twenty, each of which had participated in a different type of the healthy leisure program twice a week for nine months. First, the massage therapy type of the healthy leisure program was found to be the most effective at a change in falls efficacy. Secondly, the laughter therapy type was found to be the most effective at a change in cognition. Therefore, the healthy leisure program improved flexibility of lowincome elderly women and their positive confidence, and thereby positively influenced an improvement in cognition and prevention of falls. Therefore, this study is meaningful in the point that it may be used as a fundamental material of elderly welfare to develop a healthy leisure program taking into account the characteristics of low-income elderly women and to make use of local resources.
\end{abstract}

Keywords: Elderly Woman, Elderly Welfare, Healthy Leisure Program, Falls Efficacy, Cognition

\section{Introduction}

Today, elderly people are living longer than ever before. However, the physical disorders caused by aging and chronic diseases are negatively influencing their life. In the ageing population, the issue of health in old age has emerged as a critical social issue, and complex health risk factors of the elderly threaten their health [1]. Generally, even if elderly people have no particular diseases, they experience a variety of psychosocial losses in their ageing process, such as lowering physical function, reduced interpersonal relationship, decreased social roles, and weak economic ability. Their sense of loss caused by physical ageing leads to the social issue of the aged [2]. Therefore, in the circumstance where the ageing population is quickly increasing, it is important to manage improvements in the elderly's functional health conditions. It is reported that the biggest problems of the elderly aged over 65 are economic problems and health problems, which are highly related to the quality of life of elderly people [3]. In order to spend their long old years well, the quality of subjective life is critical. In old age when health is weak and economic resources have been reduced, the satisfaction with subjective life is related to social participation, social network, group activity, education, and relational support. In order to have a healthier and more joyful old age, the demands for exercises, health care plans, and leisure life service in old age are on the gradual rise [4].

Received (June 18, 2017), Review Result (August 24, 2017), Accepted (August 30, 2017)

* Corresponding Author 
Therefore, in old age when elderly people feel a sense of isolation easily, their participation in healthy leisure programs is very significant personally and socially. Health in old age is absolutely important and is the most fundamental and essential factor for a happy and desirable life. The health problems of the vulnerable elderly need to be handled more importantly. That is because the vulnerable elderly, including low-income elderly people, have a lower education level, a higher burden of medical cost, and more social isolation than ordinary people so that they are highly likely to get exposed to physical functional disorders and diseases. In this circumstance, to solve their health problem, it is required to have a social interest and responsibility. In particular, the physical strength of the vulnerable elderly should be aimed at a safe and normal daily life, and a variety of healthy leisure intervention activities should be taken for recovery of physical, psychological, and social functions and for vitality in life. Accordingly, it is found that healthy leisure intervention activities in old age are easily used as an alternative to drug treatment or exercise therapy [5].

As elderly people get older, their functional physical strength including muscle strength, flexibility, balance ability, and cardiovascular endurance weakens noticeably [6]. Their psychological health problem as well as physiological change has emerged as a big issue of old age. As a result, it is necessary to pay careful attention on the cognition of the elderly. With the functional decline in ageing, elderly people are more exposed to the risk of falls as they get older [7]. Most elderly people suffer from chronic diseases, and physical damage by falls may hamper their social activities.

Elderly women's risk of injuries caused by falls is more threatening than elderly men's. Elderly women have more unstable musculoskeletal structure than elderly men and have a reduction in bone density after their menopause, which increases the risk of fracture. For this reason, it is required for elderly women to take regular physical activities to prevent falls [7].

Once an elderly person has an injury from a fall, it takes at least one year to recover; he or she needs to remain unmoved often for a long time and may experience psychological difficulties such as fear of falls, anxiety, and depression [8]. Falls include a high risk of recurrence, so that they emerge as a severe health problem of the elderly. As a result, it is required to respond to falls socially.

It is reported that the physical activities of elderly people improve their physical strength, lower diverse diseases, and finally lengthen their life [3]. As such, there are many reports that physical activities of old age positively influence the healthy life of the elderly. In reality, most elderly people fail to do exercises regularly because of social, environmental, and economic restrictions. They tend to spend relatively much time doing passive leisure activities at home without body movement, such as TV watching and radio listening. A healthy leisure program helps elderly people regain their confidence, make sustainable participation in the program, and feel that they get healthier.

Therefore, this study tries to provide various types of healthy leisure programs focusing on laughter therapy, music therapy, massage therapy, and art therapy individually to low-income elderly women in local communities for the purpose of improving their health and rehabilitation; and to find the effects of the program on falls efficacy and cognition in order to help them enjoy healthy life of old age through constant health care.

\section{Study Methods}

\subsection{Study Subjects}

The subjects selected in this study were local elderly women aged over 60 who had less than $120 \%$ of the monthly average national household income, or received national basic livelihood security. The personal interest, living pattern, and health conditions of the 
subjects were surveyed by preliminary questions. Among the elderly women who volunteered to participate in the healthy leisure programs, 20 joined the laughter leisuretype program, 20 joined the music leisure-type program, 20 joined the massage leisure type program, and 20 joined the art leisure type program. The physical characteristics of the study subjects are presented in [Table 1].

Table 1. Physical Characteristics

\begin{tabular}{cccc}
\hline & Age $(\mathrm{yrs})$ & Height $(\mathrm{cm})$ & Weight $(\mathrm{kg})$ \\
\hline Laughter leisure group & $73.40 \pm 4.98$ & $153.28 \pm 6.77$ & $57.76 \pm 9.63$ \\
Music leisure group & $78.14 \pm 8.32$ & $152.1 \pm 8.10$ & $52.93 \pm 11.95$ \\
Massage leisure group & $80.5 \pm 8.73$ & $149.72 \pm 8.60$ & $57.29 \pm 13.38$ \\
Art leisure group & $74.78 \pm 5.11$ & $155.76 \pm 8.17$ & $63.43 \pm 11.37$ \\
\hline
\end{tabular}

The mean \pm Standard deviation

\subsection{Measurement Tools}

\subsubsection{Falls Efficacy}

To measure falls efficacy, this study used the tool of Fall Efficacy Scale which was developed by Tinetti, Richman and Powell [9] and was translated and used by Jang Jeongmi [10]. Cronbach's $\alpha$ was 0.93 . This tool presents fear of ten tasks for daily living in the scale of 1 to 10. A bigger number means a greater fear, or lower falls efficacy.

\subsubsection{Cognition (Mini-mental state examination-Korea; MMSE-K)}

To evaluate a level of cognitive function, this study used MMSE-K (Mini-mental state examination- Korean) questionnaire which was designed in the way of standardizing the MMSE developed by Folstein et al., [11] in consideration of the characteristics of Korean elderly people.

The questionnaire consists of time orientation, place orientation, memory registration, memory registration, attention \& calculation, language function \& visuospatial comprehension and judgment, with the total points at 30. At the beginning of the study, elderly women with mild dementia whose MMSE-K scored 15-23 points were selected.

\subsection{Data Analysis}

The data collected in the program were analyzed with the use of SPSS Ver. 20.0. To examine the interaction effect of groups (types of the leisure program) and the performance time (before and after the program participation), two-way repeated ANOVA was conducted.

\section{Study Results}

\subsection{A Change in Falls Efficacy}

Falls efficacy was evaluated before and after the program participation. The mean of each group is presented in [Table 2]. The interaction effect of performance time and groups are shown in [Table 3] [12]. There was no significant difference in the performance time of the program, but the groups were significantly different $(\mathrm{p}<.05)$. 
Table 2. The Mean of Falls Efficacy Before and After the Program Participation(points)

\begin{tabular}{ccccc}
\hline & $\begin{array}{c}\text { Laughter therapy } \\
\text { group }\end{array}$ & $\begin{array}{c}\text { Music therapy } \\
\text { group }\end{array}$ & $\begin{array}{c}\text { Massage therapy } \\
\text { group }\end{array}$ & Art therapy group \\
\hline Before & $25.69 \pm 18.02$ & $14.80 \pm 5.44$ & $54.00 \pm 26.99$ & $43.76 \pm 22.96$ \\
After & $27.69 \pm 21.17$ & $15.80 \pm 5.58$ & $54.00 \pm 26.99$ & $34.82 \pm 23.24$ \\
\hline
\end{tabular}

The mean \pm Standard deviation

Table 3. Two-way ANOVA Comparison of Falls Efficacy

\begin{tabular}{ccccc}
\hline & Sum of squares & Degree of freedom & Mean square & F \\
\hline Time & 33.817 & 1 & 33.817 & 0.164 \\
Group & 8952.127 & 3 & 2984.042 & $4.288^{*}$ \\
TimexGroup & 555.953 & 3 & 185.318 & 0.897 \\
\hline
\end{tabular}

$* \mathrm{p}<.05$

\subsection{A Change in Cognition (MMSE-K)}

To evaluate cognition, MMSE-K test was conducted. The mean of each group before and after the program participation is presented in [Table 4]. The interaction effect of the performance time and groups is shown in [Table 5]. The performance time and groups were significantly different $(\mathrm{p}<.05, \mathrm{p}<.001)$.

Table 4. MMSE-K Mean Before and After the Program Participation

\begin{tabular}{ccccc}
\hline & $\begin{array}{c}\text { Laughter recreation } \\
\text { group }\end{array}$ & $\begin{array}{c}\text { Music recreation } \\
\text { group }\end{array}$ & $\begin{array}{c}\text { Massage recreation } \\
\text { group }\end{array}$ & Art recreation group \\
\hline Before & $21.69 \pm 8.65$ & $20.40 \pm 10.47$ & $13.25 \pm 9.87$ & $23.17 \pm 4.50$ \\
After & $31.23 \pm 5.15$ & $28.00 \pm 4.63$ & $24.75 \pm 3.09$ & $29.64 \pm 3.74$ \\
\hline
\end{tabular}

The mean \pm Standard deviation

Table 5. Two-way ANOVA Comparison of MMSE-K

\begin{tabular}{ccccc}
\hline & Sum of squares & Degree of freedom & Mean square & F \\
\hline Time & 1052.200 & 1 & 1052.200 & $26.233^{* * * *}$ \\
Group & 406.165 & 3 & 135.388 & $3.922^{*}$ \\
TimexGroup & 59.705 & 3 & 19.902 & 0.496 \\
\hline
\end{tabular}

$* \mathrm{p}<.05, * * * \mathrm{p}<.001$

\section{Conclusion \& Discussion}

This study performed healthy leisure programs focusing on laughter therapy, music therapy, massage therapy, and art therapy as an effective intervention method for the elderly among therapeutic prevention activities of healthy leisure, and found the effects of 
the program on the falls efficacy and cognition of local elderly women with low income. The study results are presented as follows:

First, the score of falls efficacy was found high in the order of massage therapy group> art therapy group >laughter therapy group>music therapy group. As a result, the massage therapy type of the healthy leisure program was the most effective at falls efficacy. The score was not different depending on the performance time (before and after the program) and on the interaction of the performance timexgroup. However, the groups participating in a different type of the program were significantly different.

The result proves that among diverse healthy leisure programs used as complementary and alternative therapy, massage therapy is the most effective intervention method for falls efficacy of the elderly. Also, it shows that art therapy, laughter therapy and music therapy are very effective. In particular, it was found that massage therapy was effective at physical functions, sleep, pains, fatigue, stress, and depression and improved physical flexibility to bring about the secondary falls efficacy.

Next, with regard to cognition (MMSE-K), the score was found to be high in the order of laughter therapy group> art therapy group>massage therapy group, and thus laughter therapy was the most effective at cognition.

The result proves that the healthy leisure program is effective in improving the elderly's cognition. Therefore, the healthy leisure program of this study, which belongs to non-drug treatment, is considered to be effective at the elderly's cognition, since it includes cognition therapy, art therapy, and play therapy together.

With regard to cognition, this study showed that laughter therapy was the most effective among the four types of the healthy leisure program. In fact, laughter therapy is often used in non-medical areas in order to make the human body and soul healthy, to increase the quality of life, and to bring back happiness. Laughter therapy program was effective in reducing ageing phenomenon of the elderly and preventing diseases, and helped to improve the elderly's psychological function and their desire for joining social activities. Also, the program was reported to influence cognition positively.

An explosive rise in the population of old people draws social and scientific attention to ageing. In this circumstance, delaying ageing and providing a healthy life through physical activities are the essential factors in our society facing the ageing society. However, many elderly people fail to participate long and continuously in physical activities to improve their health and quality of life because of personal or social reasons.

This study is meaningful as follows:

It presented that the healthy leisure intervention program for the elderly positively influenced the falls efficacy and cognition of low-income elderly people, though it gave a different level of influence. Also, by comparing the effects of different types of healthy leisure program, it suggested the direction for the application of a more effective healthy leisure program for local elderly people and for elderly health care policy.

Given the study results, laughter therapy based leisure intervention activity was effective in improving the elderly's cognition, and massage therapy based leisure intervention activity was effective in improving falls efficacy. The healthy leisure program was found to increase the elderly's flexibility, improve their positive confidence, and help to enhance their cognition and prevent falls.

In conclusion, when it comes to each organization's intervention program for the vulnerable elderly, it is necessary to narrow down and take into account the physical functions and psychological health of low-income elderly people in order to develop various types of healthy leisure and therapy program, rather than the physical activity centered intervention activities or the duplicated program with no consideration of goal effect. In this way, it is possible for local elderly people to access a health leisure program more easily. Therefore, it is expected that such a program shall help to improve the quality of life of low-income elderly people and to solidify proper elderly welfare system in local communities. 


\section{References}

[1] V. Angelini, D. Cavapozzi, L. Corazzini and O. Paccagnella, "Age, Health and Life Satisfaction among Older Europeans", Soc Indic Res., vol. 105, (2012), pp. 293-308.

[2] M. W. Rogers, L. D. Hedman, M. E. Johnson, K. M. Martines and M. L. Mille, "Triggering of Protective Stepping for the Control of Human Balance: Age and Contextual Dependence”, Cognitive Brain Res., vol. 16, no. 2, (2003), pp. 192-198.

[3] K. L. Ford, A. N. Bryant and G. Kim, "Age Differences in Satisfaction with and Perceived Benefit from Mental Health Services: Results from the Collaborative Psychiatric Epidemiology Surveys", International Journal of Geriatric Psychiatry, (2012), pp. 1-10.

[4] J. J. Keysor, "Have We Oversold the Benefits of Late-life Exercise?", Journal of Gerontology: Medical Sciences, vol. 56, (2001), pp. M412-M423.

[5] B. Sang-yeol, G. Dae-sik, N. Ji-sook, L. Byeong-hun, P. Hyeong-su, P. Jong, "Relation of Physical Activity and Health-related Quality of Life in Korean Elderly", The Journal of the Korea Contents Association, vol. 10, no. 10, (2010), pp. 255-266.

[6] A. D. Akyol, "Falls in the Elderly: What Can be Done? International Nursing Review, vol. 54, no. 2, (2007), pp. 191-196.

[7] C. A. Miller, "The Connection between Drugs and Falls in Elders", Geriatric Nursing, vol. 23, (2002), pp. 109-110.

[8] D. Oliver, "Older People Who Fall: Why They Matter and What You Can Do", British Journal of Community Nursing, vol. 12, no. 11, (2007), pp. 500-507.

[9] M. Tinetti, D. Richman and L. Powell, "Falls Efficacy as a Measure of Fear of Falling", Journal of Gerontology, vol. 45, no. 6, (1990), pp. 239-243.

[10] J. Jeong-mi, "A Structural Model for Falls and Quality of Life in Elderly People Living at Home", Dissertation of Doctor's Degree at Graduate School of Kyung Hee University, (2005).

[11] M. F. Folstein, S. E. Folstein and P. R. McHugh, "Mini-mental State: A Practical Method for Grading the Cognitive State of Patients for the Clinician", Journal of Psychiatric Research, vol. 12, no. 3, (1975), pp. 189-198.

[12] L. Mi Ran and K. Seon Hee, "Change of Falls Efficacy and Cognition in Different Types of Healthy Leisure Program for Elders in Community", Proceedings of the 9th International Workshop, the Convergent Research Society Among Humanities, Sociology, Science, and Technology, (2016); Jeju, Korea. 